European journal of American studies

\title{
Space Over Time: The Urban Space in William Gibson's Techno-thriller Novels
}

Anna Krawczyk-Łaskarzewska

\section{OpenEdition}

\section{Journals}

Electronic version

URL: https://journals.openedition.org/ejas/11373

DOI: 10.4000/ejas. 11373

ISSN: 1991-9336

Publisher

European Association for American Studies

\section{Electronic reference}

Anna Krawczyk-Łaskarzewska, "Space Over Time: The Urban Space in William Gibson's Techno-thriller Novels", European journal of American studies [Online], 10-3 | 2015, document 2.6, Online since 31 December 2015, connection on 08 July 2021. URL: http://journals.openedition.org/ejas/11373 ; DOI: https://doi.org/10.4000/ejas.11373

This text was automatically generated on 8 July 2021.

Creative Commons License 


\title{
Space Over Time: The Urban Space in William Gibson's Techno-thriller Novels
}

\author{
Anna Krawczyk-Łaskarzewska
}

\section{In Gibson's fiction, to see our souls, look at our cities. Lisa Zeidner}

\section{Introduction}

This article will examine ways in which big cities are envisioned in William Gibson's three techno-thriller/ speculative noir novels: Pattern Recognition (2003), Spook Country (2007)and Zero History (2010), ${ }^{\text {}}$ frequently referred to as Blue Ant trilogy, after the name of the fictional advertising agency whose founder, Hubertus Bigend, plays a pivotal role in the books. More specifically, the functions of the urban settings in the respective stories will be briefly commented upon, taking into account the symbolic quality of the described locations and spaces as well as their thematization vis-à-vis the incrementally chaotic narratives and the limited agency of the increasingly disempowered principal characters.

In his attempt to capture the spirit of the early $21^{\text {st }}$ century, a period of growing connectivity, Gibson essentially focuses on the urban realities of the networked societies he "fantasized" about in his earlier, science fiction novels. The big, "global" cities featured in the Blue Ant trilogy, such as 
New York, Los Angeles, London, Tokyo, Moscow, or Vancouver, have their apparent, real life counterparts, yet the thoroughly mediatized nature of the cityscapes fashioned by Gibson makes it difficult to establish a clearcut boundary between the real and the imagined, the strange and the familiar, the authentic and the manufactured.

While the semiotic excess in the fictionalized cities is usually structured and interpreted mainly using capitalism as a point of reference, Gibson's literary representation of all things urban tends to rely on juxtaposing the quasipsychogeographic experiences and reflections of his fictitious protagonists with spatial navigation tools, such as GPS, Google Earth, Google Maps, Wikipedia, social networking media, etc. However, even those instantly trackable and seemingly explicit settings retain their enigmatic instability, very much in accordance with the events taking place in them.

In what follows, I will attempt to clarify two points. Firstly, in Gibson's more recent literary oeuvre cities appear to be unknowable and socially unsustainable, especially as regards the inhabitants' chances of gaining power to influence and transform their urban habitats. Secondly, his protagonists' inability to fully make sense of cities results from the fact that they are constantly dealing with their atemporal representations. ${ }^{2}$ In other words, although I do not intend to question the assumption that spatial thinking is "a general human tendency" and "spatial elements play an important role in fabulas" (Bal 215), nevertheless, I contend that Gibson tends to privilege space over time for more sinister reasons: The urban environment he describes and filters through his protagonists' minds

is apparently not the end-result of an historical process, but one which seems ready-made, defined and homogenised through the corporate logo, with any sense of contextualising this process denied through the fossilisation of history that is a result of 'heritage'. In this environment we do not encounter man the maker, but man the consumer. This is not a world that is brought into being by Gibson's narrative, but which is already there, already 'made' and described in terms of the brand names which have made it. (Skeates 8-9) ${ }^{3}$ 


\section{Sustainable Cities and Binaries}

Although the problems with distinguishing the modernday city and "the urban non-spaces of postmodernity" (Skeates 6) is beyond the scope of the present analysis, it seems necessary at this point to hint at some consequences of thinking about cities in terms of their sustainability or lack thereof. Of specific interest to me is the discordance between various definitions of sustainability in terms of how they employ the frame of space and time. To illustrate this discordance, Matthias Berger invokes the most frequently cited approach to sustainability, according to which "[s]ustainable development is development that meets the needs of the present without compromising the ability of future generations to meet their own needs" (365). ${ }^{4}$ This popular definition privileges growth in time, rather than in space, whereas in the case of cities a more static definition would probably make more sense. For instance, one such "space-friendly" definition characterizes sustainability as "the ability to be sustained, supported, upheld, or confirmed, ${ }_{5}$ while others might prevent us from conflating sustainability and self-sufficiency by treating the city as "a metabolism, as exchange of stocks flows, not as aggregation of individuals' behavior; yet embedded within something larger, alternatively either seen as hinterland, habitat, nation or planet Earth" (Berger 367-8).

There are several other issues worth mentioning in the context of sustainability. To begin with, as Berger rightly observes, sustainability is "essentially a binary conceptmeaning that either something is sustainable or it is not sustainable" (370); such a binary opposition might be troubling and unsatisfactory especially in fiction, which favors more nuanced distinctions. Furthermore, Berger argues that "by definition, cities are the counterparts to the hinterland, and thus they axiomatically should be and are unsustainable" $(365,366)$. Additionally, he reminds us that "[u]nsustainable cities have been studied for many decades, even from different perspectives, but almost entirely as an expression with negative connotation" (366), a conclusion shared by Leif Jerram:

While occasionally we see 'urban' being used to denote 'cool' and 'sophisticated', 'liberal' and 'progressive', 'free' and adventurous', too often our cities, over the last hundred years, have been used as a shorthand for our defects, our failures, and our disappointments. 
When it comes to our cities, we have the self-esteem of a battered wife. (Jerram 386)

There is, naturally, a larger context for issues connected with sustainability. For the sake of brevity, I will mention only cursorily the problem of definitions which suit particular agendas. For example, environmentalists claim that the Brundtland Report definition is flawed as it eschews ecological responsibility while extolling the social dimension of sustainability: Instead, they "define sustainability as the ability to continue a defined behavior indefinitely...because if environmental sustainability...is not achieved, then none of the zillions of other types of sustainability matter." ${ }^{\circ}$ Of greatest relevance to me, however, is the fact that Gibson never found it entirely feasible to examine cities in processual terms, as entities developing across specific time frames.

\section{Troubling Timelessness}

The rationale for Gibson's consistent atemporality is expounded on, among other characters, by Hubertus Bigend, an enigmatic, highly influential mogul who orchestrates the events in each of the three novels, and who offers a general observation on the possibility of registering a more or less linear growth in the era of rapidly shrinking future:

"Of course," he says, "we have no idea, now, of who or what the inhabitants of our future might be. In that sense, we have no future. Not in the sense that our grandparents had a future, or thought they did. Fully imagined cultural futures were the luxury of another day, one in which 'now' was of some greater duration. For us, of course, things can change so abruptly, so violently, so profoundly, that futures like our grandparents' have insufficient 'now' to stand on. We have no future because our present is too volatile." $\mathrm{He}$ smiles, a version of Tom Cruise with too many teeth, and longer, but still very white. "We have only risk management. The spinning of the given moment's scenarios. Pattern recognition." (PR 57)

Bigend is a character whose arc develops consistently and with an inexorable logic, if to the probable detriment of the humanity: he wants more information and more influence, and in the course of the trilogy he not only becomes more and more controlling, but is also able to control his employees more efficiently. However, the mogul's greed does not make him oblivious to the 
consequences of living in accelerated times. For instance, Bigend's remark that "[e]verything, today, is to some extent the reflection of something else" ( $P R$ 68) spells out a significant problem with describing the $21^{\text {st }}$ century world, namely the absence of any genuine novelty and the ubiquity of corporate-friendly, generic, smug blandness. Because of the effective insidiousness of coolhunting, even the growth of subcultures is no longer spontaneous, unaffected by viral marketing and other commercial strategies.

Coupled with the fact that "the spatialisation of the world takes precedence over chronological orderings of time" (Grierson 6) is the sense of reaching a threshold beyond which our civilization cannot progress anymore. A few years ago Bruce Sterling defined the situation as one of "growing disorder": "Historical narrative . . . is simply no longer mapped onto the objective facts of the decade" and "[t]he maps in our hands don't match the territory," and thus we are doomed to mere "attempts at sustainability." He went as far as to compare living in an "atemporal network culture" to "moving into a new town," where the creative artists have learned to "take elements of past, present, and future and just collide 'em together" in an act of some "Frankenstein mashup." Sterling's insistence on refusing "the awe of the future" and "reverence to the past" sounds like an opportunistic, but rational contingency plan: the only way to go in an atemporal world, where future has already arrived, is to reduce the past and the future even further and to focus on living-in-the-moment. The alternative is not exactly encouraging: History "flatten[ed] into serviceable narratives, from records of financial dataa credit check database returns the information that a character has "zero history"-to brand-formation and marketing strategy" (Purdon).

\section{Tough Cities}

In the mid-seventies of the $20^{\text {th }}$ century Jonathan Raban published Soft City, a quasi-documentary collection of essays which focused on the nature of experiencing the modern-day city. The blurb on the cover of the book introduced an interesting and valid distinction between the subjective perception of urban settings and their objective, quantifiable functioning. Raban's soft city "as we imagine it is as real, maybe more real, than the hard city that we can locate in maps and statistics. The soft city is a private place; 
everyone lives in his or her own soft city." In the first chapter of the book a reciprocal connection is established between cities and the people inhabiting and/or visiting them. The city

goes soft; it awaits the imprint of an identity. It invites you to remake it, to consolidate it into a shape you can live in. You, too. Decide who you are, and the city will again assume a fixed form round you. Decide what it is, and your own identity will be revealed. (9)

12 Compared to "the soft city of illusion, myth, aspiration, nightmare" (Raban 2), Gibson's cities seem to be located somewhere in-between, in a liminal space where hardness and softness are intertwined. In spite of clearly defined space and time coordinates, those urban mazes often become almost unrecognizable and are experienced in intensely personal ways. Moreover, the highly subjective geographies so alluringly described by Raban are expanded by Gibson in a rather ambiguous fashion. Depending on his cosmopolitan protagonists' backgrounds and obsessions, the cities portrayed in the Blue Ant trilogy often function as simulacra of simulacra and as zones of both privilege and destitution; as repositories of meaningful symbols and empty signifiers; as sites where "obsolescent artefacts" become "semiotic phantoms" (Aguirre 126), at the same time as citizens are affected by very real constraints. Ultimately, toughness is what both the soft and the hard city have in common, but Gibson's pessimism brings to mind early 20th century treatises whose authorsphilosophers, scholars, sociologists-shared the conviction that "the city fundamentally corrodes every form of real community and fulfilling human relationship altogether" and that it is "ultimately an agent of disintegration of human relationships and atomization of the human psyche" (Jerram 392).

The common motifs and themes in the trilogy are easily discernible. Each of the novels is set around a nodal event happening in the real world and exerting a significant influence on the protagonists, but whether it is the 9/11 tragedy, the 2003 invasion of Iraq or the financial crisis of 2008,7 the main characters' quests are accompanied by the drive to decipher urban reality. Each object of each of the quests turns out to be somewhat ridiculous, a Macguffin whose sole purpose has been to drive the plot. It is the guessing game on the part of the protagonists and their peculiar ways of responding to the incomprehensible, "illdefined, semi-public, vulnerable...illegible and threatening" 
urban environments that matter the most (Meades 174). The perverted flânerie Gibson is toying with is hardly surprising in cities perceived as overflows of products and images.

As regards narrative patterns, the story in Pattern Recognition is seen largely through Cayce Pollard's mind, Spook Country braids into three main plotlines, whereas in the case of Zero History we are following two characters whose task is to find a mysterious creator of a new brilliantly designed product. However, whereas coolhunter Cayce was able to retain anonymity and independence after completing her mission, neither the artistically inclined and unconventionally thinking Hollis nor the recovering exaddict and translator Milgrim can enjoy a sense of agency. They turn out to be pawns on the chessboard, in a game configured and controlled by Bigend. Needless to say, the winner (Bigend) takes it all; he is able to outmaneuver every single competitor, from government agents to arms dealers and mobsters.

\section{Pattern Recognition}

In Pattern Recognition, members of a web chat group obsess over mysterious film clips which are available online and referred to as "footage." One of those members is Cayce Pollard, a freelancer who has a very special ability, namely, she quickly detects first symptoms of something that might become a trend or a new fashion. Paradoxically, in spite of her unusual skills she suffers from anxiety attacks caused by the surplus of logos, and suspects almost everyone of conspiring against her. Hired by her rich boss, the already mentioned Hubertus Bigend, to track down the creator of a series of anonymous, artistic film clips via the internet, Cayce travels to various big cities and while roaming about London, Moscow, New York and Tokyo, she experiences confusion and sadness (her father, a retired C.I.A. man, was in New York on Sept. 11, 2001, and is presumed dead). Only after meeting the person who created the clips, she is reminded of the redeeming power of art and is able to shake off her emotional detachment, create new personal patterns, and achieve a degree of closure.

Naturally, Cayce's presence in the above mentioned cities is very much a result of belonging to a privileged elite and her urban experience is limited, dictated by the socially 
and economically confined nature of the locations (e.g., the only way she will finally see Tokyo is through the windows of her hotel, and in the hotel fitness center). Additionally, Cayce's sense of dislocation might stem from filtering the reality through her Americanness. For example, London is nearly always featured as a place refracted by the prism of American urban spaces: relational, never quite autonomous - simply a mirror-world, and perhaps aptly so, considering the logic of the world in which simulacra prevail.

Even more exotic cities do not encourage Cayce to drop the habit of gazing and interpreting them like a Westerner. That is why, having found herself on Moscow's Arbat, she immediately compares it to Oxford Street $(P R$ 310), although the location does not look like Oxford Street at all. Moscow is one of the global cities and yet Cayce usually perceives it as having no individual, idiosyncratic presence, even though it cannot be reduced to the position of a mirror-world in her imagination. It is possible to know, describe and maybe even understand Moscow mostly through US-specific, movie clichés. The irony of the situation is quite striking: A symbol of an empire is depicted by means of symbols forever associated with another empire. The following "pale simulacra" quotation only confirms the overall impression that we learn nothing about Moscow. After 9/11 (but also after the Cold War) nothing is the same, even the ways of simulating past and foreign cultures:

The lounge has the October theme in spades, haystacksized arrangements of dried flowers flanking leaf-strewn sideboards piled with pale simulacra of gourds, worryingly skull-like. Much brownish mirror, darkly veined with gold.

The girl with green boots is here, though not wearing them; Cayce recognizes the snakeskin flames, deployed to maximum advantage atop a barstool. At least a dozen of this one's colleagues seem to have negotiated security as well, this evening, and attend to a clientele consisting entirely of large, clean-shaven, short-haired, remarkably square-headed men in dark suits. Like some lost America, down to blue strata of cigarette smoke and the completely unironic deployment of the Frank Sinatra, through both of which the gestures of these men are carving out the shapes of triumph and empire, defeat and frustration. (PR 312-13)

Cayce's father, Win Pollard, used to work in Moscow, but the city "never seemed like a real place" to her, "more a fairy tale" ( $P R$ 265). When she arrives in Moscow for 
professional reasons, she notices its ugly, bombastic architecture and general dilapidation, and drivers changing lanes "in a way that gives her little confidence" ( $P R$ 269). Her Moscow is merely an instance of the imaginary, unruly Eastern European other.

Gibson's fiction has been said to occupy a "borderland territory between unlikely truths and likely falsehoods"; his is "a disorientating world of nouns, mirroring our own world, where nouns-things, that is-are dizzyingly paramount" and that world of nouns or things "eats itself like an ouroboros" (Thomas). However, the concluding scenes of Pattern Recognition demonstrate Cayce's readiness to question comforting binary oppositions:

Cayce looks from Sergei to Marchwinska-Wyrwal to Bigend, then to Parkaboy, feeling much of the recent weirdness of her life shift beneath her, rearranging itself according to a new paradigm of history. Not a comfortable sensation, like Soho crawling on its own accord up Primrose Hill, because it has discovered that it belongs there, and has no other choice. But, as Win had taught her, the actual conspiracy is not so often about us; we are most often the merest of cogs in larger plans.....

It occurs to her then that the meal has been entirely free of toasts, and that she's always heard that a multitude of them are to be expected at a Russian meal. But perhaps, she thinks, this isn't a Russian meal. Perhaps it's a meal in that country without borders that Bigend strives to hail from, a meal in a world where there are no mirrors to find yourself on the other side of, all experience having been reduced, by the spectral hand of marketing, to price-point variations on the same thing. ( $P R$ 341)

20 Cayce's inability to read Russian has interesting consequences: It alleviates her logophobia, makes her immune to the excessive commercialization of the city districts and, paradoxically, able to see more. At the beginning of the Moscow episode, her experience seems to be delimited by the Lonely Planet view of the city. On completing her mission she is at least able to re-invent Moscow, frame it in a larger context, although this more global outlook means paying less attention to what might make the city unique, different. 


\section{Spook Country}

Out of the three intersecting plotlines that dominate Spook Country, the most important one concerns Hollis Henry, once a popular rock vocalist and now a music journalist. The task she is given by Bigend consists in finding and interviewing a fashionable artist Bobby Chombo, who specializes in locative art and, additionally, is an expert in military navigation systems. While trying to keep track of a shipping container whose destination and cargo are revealed in the final chapters of the story, Hollis will have to travel to several cities.

The urban world in the second instalment of Gibson's trilogy seems to have become even more unfamiliar and incomprehensible. Art, marketing and all things military converge here with frustrating efficiency, and the knowledge gained by the characters will be used to facilitate crime, rather than redemption. The main characters are constantly spied upon, yet in a sense they have already come to terms with the surveillance. They are under no illusion that they can change things for the better, either. The deliberately ambiguous title of the novel refers to covertness as a dominant modus operandi as well as to the spectral presences populating the urban environment. The good old-fashioned flânerie, even in its perverted version, is practically absent here; it is replaced by Systema alertness: the readiness to fight and be in absolute control of emotions at the same time.

Łos Angeles, where locative art makes it possible to recreate things which no longer exist (yet another decontextualizing, atemporal gesture), albeit for very limited, privileged audiences, is also a place where anything can become a reality. It functions as a setting completely emptied of meanings. The possibilities of things happening there are limitless precisely because LA is unreal by default:

The air was full of the dry and stinging detritus of the palms. You are, she told herself, crazy. But that seemed for the moment abundantly okay, even though she knew that this was not a salubrious stretch for any woman, particularly alone. Nor for any pedestrian, this time of the morning. Yet this weather, this moment of anomalous L.A. climate, seemed to have swept any usual sense of threat aside. The street was as empty as that moment in the film just prior to Godzilla's first footfall. Palms straining, the very air shuddering, and 
Hollis, now hooded blackly, striding determinedly on. Sheets of newspaper and handouts from clubs tumbled past her ankles. A police car whizzed past, headed in the direction of Tower. Its driver, slumped resolutely behind the wheel, paid her no attention. To serve, she remembered, and protect. The wind reversed giddily, whipping her hood back and performing an instant redo on her hair. Which was in need of one anyway, she reminded herself. (SC 13)

Spook Country offers a modified concept of space, too: It is neatly tagged, URL-dependent, GPS-described, bracketed by Augmented Reality technology, with the potential to be divided into an endless number of channels, to suit the needs of its fragmented communities and growingly paranoid citizens. The real life counterparts of such separate spaces include ghettos for the masses and enclaves for the obscenely rich, where CCTV cameras, gates, nets, and barbed wire make access difficult and epitomize the Deleuzian paradigm of "societies of control." Taking into account these disparate points of reference, it is easy to understand why even the main character in the novel is unable to form a coherent picture of urban realities, not to mention reality as such:

Hollis Henry is, in essence, a modernist character in a postmodern novel, a person seeking definitive answers in a world surfeit with information. Even though in the end she finds the information she seeks-that is, the location of the shipping container filled with U.S. currency-she cannot know its significance, beyond the fact that it is part of a shell game of sorts in which meaning is endlessly deferred. (Henthorne 27)

\section{Zero History}

The very first paragraph suggests that the motifs of quest, atemporality and flattening of history will be explored in great detail:

Inchmale hailed a cab for her, the kind that had always been black, when she'd first known this city. Pearlescent silver, this one. Glyphed in Prussian blue, advertising something German, banking services or business software; a smoother simulacrum of its black ancestors, its faux-leather upholstery a shade of orthopedic fawn.

26 Cabinet, a hotel/club in Portman Square, London, is the first location described in detail: a site of privilege, but mostly a 
part of the mirror world. A sense of disorientation prevails, which ties in consistently with the gradual loss of agency for the protagonists of the novel. The city is a text/pattern which is growingly difficult to decode. On his route from Heathrow, having entered Euston Road, Milgrim ponders over the enigmatic nature of the cityscape:

Like entering a game, a layout, something flat and mazed, arbitrarily but fractally constructed from beautifully detailed but somehow unreal buildings, its order perhaps shuffled since the last time he'd been here. The pixels that comprised it were familiar, but it remained only provisionally mapped, a protean territory, a box of tricks, some possibly even benign. ( $\mathrm{ZH} \mathrm{37)}$

Hubertus Bigend hires, separately, Milgrim and Hollis, the protagonists of Spook Country. The former is supposed to gain access to and photograph a piece of rare military clothing, while the latter's task involves tracking the identity of the person who designed the Gabriel Hounds, yet another mysterious brand which fascinates the head of Blue Ant. ${ }^{8}$ Having experienced the consequences of the financial crisis, Hollis is forced to accept the job: "the world has become a place in which choice-ethical and otherwise-is a luxury to which few have access" (Henthorne 61), but then, the world she is living in is "a world where nearly everyone is losing control of their lives" (62). If Spook Country read like a drug-induced memoir of a very paranoid person, Zero History is striking for the disjointed nature of memories and a permanent sense of dislocation. As usual, the nomadic lifestyle of the protagonists is not conducive to making sense of the cities.

6haracteristically enough, the cities Gibson describes in Zero History cannot even be perceived in isolation, as self-contained, unique entities: Everything in them resembles something or mirrors something; each location brings associations with an alternative universe, rather than with its own past and present. Gibson's protagonists often have the impression that the urban setting they are dealing with is only superficially autonomous. For example, at some point Holly realizes that her memories of touring with her band have little to do with the reality of the cities she visited. The chaotic way in which she frames her experience further reflects the impossibility of grasping the essence of an Australian city:

Her Melbourne was a collage, a mash-up, like a Canadianized Los Angeles, Anglo-Colonial Victorian amid a terraformed sprawl of suburbs. All of the larger 
trees in Los Angeles, Inchmale had told her, were Australian. She supposed the ones in Melbourne were as well. The city in which she was imagining Clammy now wasn't real. A stand-in, something patched together from what little she had available. She felt a sudden, intense urge to go there. Not to whatever the real Melbourne might be, but to this sunny and approximate sham. ( $\mathrm{ZH}$ 77-8)

However, what makes Zero History really worth attention is how the old paradigm of flânerie gets repurposed, transformed into an all-encompassing metaphor. For example, Meredith, a perfunctory character, recalls her "[i]ntensely nomadic" ( $Z H$ 117) experience as a young model working in various cities and having to walk everywhere because of her meagre income. After she quit modelling, she decided to become a designer herself and the first thing she designed was a pair of sneakers that were both good-looking and didn't fall apart, but that would be "somehow...untainted by fashion" ( $Z H$ 119).

What my friends and I were going through as models was just a reflection of something bigger, broader. Everyone was waiting for their check. The whole industry wobbles along, really, like a shopping cart with a missing wheel. You can only keep it moving if you lean on it a certain way and keep pushing, but if you stop, it tips over. Season to season, show to show, you keep it moving. ( $Z H$ 118)

In order to understand things better (in this case the history of shoes and their cultural significance) Meredith enrolled in a fashion college in London. She moved to the UK capital, or rather in her own words, "simply stopped moving. In London" (119). It would be difficult not to see the irony of juxtaposing a reluctant nomad and the modernday city, which is "in constant movement" (Rykwert 265): A successful shoe designer seems no longer interested in making good use of her product because, after all, "[t]o walk is to lack a place" (de Certeau 103).

Interestingly, it turns out one of Meredith's American friends used to wear a jacket which was to become the Hounds brand, and which was designed by someone from Chicago. It is strongly implied in the novel that Cayce Pollard may have been that person. The story of the mysterious designer-hobbyist makes Meredith realize that she is on the right track, that the sneakers she designed are the real thing precisely because they are not tied to a particular time frame: “Things that weren't tied to the 
present moment. Not to any moment, really, so not retro either" (ZH 120).

Similarly, not walking, or rather, notwalking at all is crucial in the case of Milgrim:

Milgrim had never liked the City. It had always seemed too monolithic, though to some older scale of monolith. Too few hiding places. A lack of spaces in between. It had been turning its back on people like himself for centuries, and made him feel like a rat running along a baseboard devoid of holes. ( $\mathrm{ZH} 255$ )

The heels of Milgrim's Tanky \& Tojo brogues, as he sat astride the high, raked pillion of Benny's Yamaha, didn't quite touch the cobbles of this tiny square. Something about the angle of his feet recalled some childhood line-drawing from Don Quixote, though whether those feet had been the knight's or Sancho Panza's, he didn't know. ( $\mathrm{ZH}$ 361)

For Milgrim, who makes a living as a translator and interpreter, the only truly reliable way to know the city, to understand it, is via media:

He looked down at the screen, the glowing map. Saw it as a window into the city's underlying fabric, as though he held something from which a rectangular chip of London's surface had been pried, revealing a substrate of bright code. But really, wasn't the opposite true, the city the code that underlay the map? There was an expression about that, but he'd never understood it, and now couldn't remember how it went. The territory wasn't the map? ZH (370)

Like Hollis, Milgrim is an outsider, but not a cosmopolitan as she is. "What he discovers as he becomes a more fullyrounded person is that the world itself has flattened, the differences between London and Paris, for example, becoming almost negligible, being occupied by the same sorts of people doing the same sorts of things" (Henthorne 83). When in the final chapter of the novel Milgrim becomes aware of the fact that for some time he has been given placebo treatment, there is a sense that he has also been cured of illusions.

\section{Conclusion: The Creatives' Complicity}

In Pattern Recognition we are provided with numerous opportunities to assess the female protagonist's state of mind, but only once in the course of the story Cayce seems to be experiencing remorse for the privileged lifestyle she has embraced:

Leaving Neal's Yard and the Pilates studio, she tries to become just another lost tourist, though she knows she'll never be one. Like Magda going out to spread 
whatever shabby micromeme her Blue Ant subsidiary requires her to, Cayce knows that she is, and has long been, complicit. Though in what, exactly, is harder to say. Complicit in whatever it is that gradually makes London and New York feel more like each other, that dissolves the membranes between mirror-worlds. ( $P R$ 194)

Even if, in retrospect, the first novel of the Blue Ant trilogy seems reasonably optimistic (after all, Cayce manages to find the maker of the mysterious footage and is transformed spiritually thanks to Nora's art), nevertheless it sows the seeds of inevitable failure. It is the so-called creatives, installation/digital media artists, designers, coolhunters, rock musicians, filmmakers, painters who save the day. But these talented creatures are also vulnerable to cooptation, and their complicity has the potential of turning the world into a nightmare.

Bigend's motivation in Zero History is truly ambitious and perplexing at the same time: To find "the order flow," to know the future or at least "a very tiny slice of the future" ( $\mathrm{ZH} \mathrm{401).} \mathrm{Ironically,} \mathrm{he} \mathrm{gets} \mathrm{what} \mathrm{he} \mathrm{wants} \mathrm{thanks} \mathrm{to} \mathrm{the}$ brilliance of an artist (the order flow is revealed to him inadvertently by Chombo), rather than his limitless financial resources. The end of the Blue Ant trilogy leaves no illusion as to the way things are turning out; the creatives are, in varying degrees, selling out to parasitic corporate America, not bothering too much about those less privileged.

In a way, Gibson's novels constitute, perhaps inadvertently, a depressing, if not wholly unexpected, postscript to the work of American urban studies theorist Richard Florida, who in 2002 predicted "the rise of creativity as a fundamental economic driver, and the rise of a new social class, the Creative Class" (vii), and expressed the conviction that "the dawning of the Creative Age has ushered in a newfound respect for livability and sustainability" (x). Florida defended himself against criticisms that his vision of sustainability privileges the Creatives over other classes, by stating that the most important task ahead is "to unleash the creative energies, talent, and potential of everyone-to build a society that acknowledges and nurtures the creativity of each and every human being" (xi):

a shared and sustainable prosperity that improves human well-being and happiness and restores meaning and purpose to life. We must shift from a way of life that valorizes consumption, in which we take our identities 
from the branded characteristics of the goods we purchase, to one that enables us to develop our talents and our individuality, to realize our truest selves through our work and other activities. Our fledgling Creative Economy needs to give way to a fully Creative Society, one that is more just, more equitable, more sustainable, and more prosperous: our economic future depends on it. (Florida xiv)

Volker Kirchberg and Sacha Kagan argue that "Florida's emphasis on the creative class (and the 'super-creative core') is tainted by implicit demands for an unsustainable urban development" (137), leading to further polarization and homogenization of the urban environment (138). Great global cities might seem "unprecedentedly desirable," but they are also "socially bifurcated" (Abbott 125) and resemble "elite citadels," "turning into vast gated communities where the one per cent reproduces itself" (Kuper).

Odbviously modifying Lefebvre's idea of "the right to the city," wherein urban renewal "cannot but depend on the presence and action of the working class, the only one to put an end to a segregation directed essentially against it" (Lefebvre 154), and repurposing Robert Merton and Elinor Barber's 1958 study The Travels and Adventures of Serendipity (which highlighted the importance of accidental discoveries in science), Kirchberg and Kagan propose "the right to serendipity" (141), where the possibility of chance events is taken into account, which, coupled with "sustainable creativity" and resilience might prevent the neo-liberal model of economy from being the sole factor influencing urban development.

The Blue Ant trilogy presents a vision of the globalized world in which little is left to chance and highly advanced technology does not necessarily improve the cause of decent living conditions for all. On a more spiritual and emotional plane, "[a] doom-laden idea that everything may be connected persists even while individuals are striving, and often failing, for personal connections amid a technological wonderland" (Taylor). The fictionalized cosmopolitan wanderers traversing big cities in the $21^{\text {st }}$ century, and losing sight of the bigger picture, are a sign of the times. Perhaps they mark a necessary transition stage between the old "analog system" and the more anarchic and more participatory network culture (Sterling). Perhaps Sterling is right in claiming that atemporality "has a built in 
expiration date. It's not going to last forever. It's not a perfect explanation, it's a contingent explanation for contingent times." Meanwhile, we are left with pockets of resistance which, like small parallel universes, might become a remedy to the atemporal power takeover. Space over time, indeed.

\section{BIBLIOGRAPHY}

Abbott Carl. "Cyberpunk Cities: Science Fiction Meets Urban Theory." Journal of Planning Education and Research 27 (2007): 122-131.

Aguirre, Peio. "Semiotic Ghosts: Science Fiction and Historicism." Afterall: A Journal of Art, Context, and Enquiry 28 (Autumn/Winter 2011): 124-134.

Bal, Mieke. Narratology. Introduction to the Theory of Narrative. Toronto: University of Toronto Press, 1997.

Berger, Matthias. "The Unsustainable City." Sustainability 6 (2014): 365-374.

De Certeau, Michel. The Practice of Everyday Life, trans. Steven Rendall. Berkeley, CA: University of California Press, 1984.

Deleuze, Gilles. "Postscript on Control Societies."

Negotiations. Trans. Martin Joughin, 177-182. New York:

Columbia Univ. Press, 1990.

Florida, Richard. The Rise of the Creative Class, Revisited. $10^{\text {th }}$ Anniversary Edition. New York: Basic Books, 2012.

Gibson, William. Pattern Recognition. New York: Berkley, 2005.

. Spook Country. New York: Berkley, 2009.

Zero History. New York: Putnam, 2010.

Grierson, Elizabeth M. "From Cemeteries to Cyberspace:

Identity and a Globally Technologised Age." Working Papers in Communication (December 2001): 1-12.

Henthorne, Tom. William Gibson: A Literary Companion. Jefferson, NC, and London: McFarland, 2011. 
Jerram, Leif. Streetlife. The Untold History of Europe's

Twentieth Century. Oxford: Oxford University Press. 2011.

Kilian, Eveline. "Review of Imagining London, 1770-1900." Journal for the Studies of British Cultures 12.1 (2005): 88-90.

Kirchberg, Volker and Sacha Kagan. "The Roles of Artists in the Emergence of Creative Sustainable Cities: Theoretical Clues and Empirical Illustrations." City, Culture and Society 4 (2013): 137-152.

Kuper, Simon. "International Cities Are Turning Into 'Elite Citadels.'” The Financial Times 1 June 2013.

Lefebvre, Henri. "The Right to the City." Henri Lefebvre Writing on Cities. Translated and edited by Eleonore Kofman and Elizabeth Lebas. Oxford, Malden: WileyBlackwell, 1996. 147-159.

Meades, Jonathan. "Postmodernism to Ghost-Modernism." Museum Without Walls. London: Unbound, 2013. 170-184.

Purdon, James. "Zero History by William Gibson." Guardian 12 Sept. 2010.

Raban, Jonathan. Soft City. London: Flamingo, 1984.

Rykwert, Joseph. The Seduction of Place. The History and Future of the City. Oxford: Oxford University Press, 2009.

Skeates, Richard. "The Infinite City." City 2.8 (1997): 6-20.

Sterling, Bruce. "Atemporality for the Creative Artist transcript."Wired.com 25 Feb. 2010.

"Sustainability." Thwink.org 2014.

Taylor, Art. "Book World: William Gibson's Zero History." The Washington Post 11 Sept. 2010.

Thomas, Scarlett. "Networking." New York Times 8 Sept. 2010.

Zeidner, Lisa. "Pattern Recognition: The Coolhunter." The New York Times 19 Jan. 2003.

\section{NOTES}

1. Henceforth, all references to novels under discussion will be abbreviated by using the initial capital letters of the respective titles: $P R, S C$, and $Z H$,

2. See also Kilian 88. 
3. Skeates made this comment in reference to Gibson's first science fiction trilogy and short stories, but the generalization holds true for the writer's non-science fiction novels as well, perhaps to an even larger extent.

4. To be exact, the above definition of sustainable development comes fromOur Common Future report (known also as the Brundtland Report), by the World Commission on Environment and Development, issued in 1987.

5. See the definition at http://dictionary.reference.com/browse/ sustainability.

6. http://www.thwink.org/sustain/glossary/Sustainability.htm.

7. As per Gibson's statements on his blog and in numerous promotional interviews. See also Henthorne 126.

8. Ironically, in real life Lucinda Trask designed a clothing line based on the works of WG. She called it Hounds. See http://like-clothing.biz/ and http://like-clothing.biz/pdf/like-hounds-lookbook.pdf. Every page of the brochure has an insert with a photo of a cityscape.

\section{INDEX}

Keywords: atemporality, city, flânerie, locative art, mediatization, mirror-world, simulacra, space, sustainability.

\section{AUTHOR}

\section{ANNA KRAWCZYK-ŁASKARZEWSKA}

University of Warmia and MazuryAnna Krawczyk-Łaskarzewska is teaching at the University of Warmia and Mazury in Olsztyn. She published articles and edited volumes devoted to film and TV adaptations, book illustrations and other pop/visual culture phenomena, as well as William Gibson's prose and cultural representations of the city. Her current research focuses on the theoretical and practical aspects of reimagining and repurposing iconic literary characters. 